\title{
Refractory WHO Grade III Glioma
}

National Cancer Institute

\section{Source}

National Cancer Institute. Refractory WHO Grade III Glioma. NCI Thesaurus. Code C153865.

A WHO grade III glioma that is resistant to treatment. 